By Mort Kothmann

\section{Exciting Changes in SRM Publications}

Welcome to the new Rangelands. You will notice some changes in this issue of Rangelands. Gary Frasier, Editor-In-Chief, the Rangelands Steering Committee (David Bradford, Chair), and Alliance Communication Group (ACG) have worked together to reshape this important membership service publication. You will find new departments, special features, and special themes, all in full color. I hope you appreciate and are proud of this new look and content of Rangelands. This represents the combined efforts of many of your fellow SRM members over the past 2 years. We expect the new Rangelands to not only be a great service to our members, but to be a significant outreach tool to further the mission of SRM in the education of students and the public on the importance and management of rangelands.

Have you seen the January 2005 issue of the Journal of Range Management, now Rangeland Ecology $\mathcal{G}$ Management? It not only has a new name, it has a whole new look from the front color cover to the back. Keith Owens and the Associate Editors have been working with ACG for the past year to strengthen this publication and make it an even more effective science publication. This effort has been guided by the Journal of Range Management Steering Committee (Dave Engle, Chair) for the past 2 years. We welcome your comments on the changes that have been made in Rangelands and Rangeland Ecology \& Management.

We hope you were at the 58th Annual Meeting of SRM in Fort Worth, Texas, in February 2005. This meeting is shaping up to be another record-breaking meeting following the tremendous meeting in Salt Lake City, Utah, last January. The SRM Annual Meetings are exciting and informative. There will be over 400 technical papers presented that represent the full biodiversity of the rangelands we love and manage. We expect nearly 2,000 professionals with extensive opportunities for networking. Federal agencies will have representatives onsite to interview for positions, and with authority to "hire-on-site." The entertainment will be outstanding and the venue is excellent. If you haven't made it to one of these events recently, start making your plans to be in Vancouver, British Columbia, next February 2006 for the 59 th AM of SRM.

The members of SRM are working on many programs and activities. The new journals and the Annual Meeting are just a sample of the excellent work that is ongoing in SRM. It is a privilege to be a part of an organization where members care about the resource, support the mission of SRM, and care for each other. Keep up the great work and together let's make the next 60 years of SRM even better than the first 60 years.

Author is President, Society for Range Management, and is with Texas AE'M University, Department Rangeland Ecology E̋ Management, College Station, TX 77843-0001. 